primary efficacy end point was the improvement of ASDAS-CRP. Secondary end points included ASAS 20, ASAS 40, ASAS 5/6, ASAS partial remission and BASDAI. Safety was evaluated during scheduled visits.

Results: 123 patients with active nr-axSpA were enrolled between April 19, 2014, and July 10,2015 . The mean age of the $123 \mathrm{nr}-\mathrm{SpA}$ patients was $(25.3 \pm 5.9)$ years. The ASDAS-CRP and BASDAI decrease from $2.7 \pm 0.9$ to $0.7 \pm 0.4$, from $4.5 \pm 1.5$ to $0.9 \pm 0.8$, respectively between weeks 0 and 24 . The patients achieved the ASDAS-CRP $<2.1$ was $96.7 \%$. ASDAS-CRP major and important improvement were achieved by $41.4 \%, 79.8 \%$, respectively at weeks 24 . ASAS 20 , ASAS 40 , ASAS5 $/ 6$ and ASAS partial remission were achieved by $75.0 \%, 54.8 \%$, $64.5 \%, 89.3 \%$, respectively at weeks 24 . Yisaipu-treatment was associated with statistically significant improvements in all parameters, including BASFI, BASMI, PGA, PhGA, ESR and CRP concentrations. Most adverse events in the open-label phase were mild or moderate in severity.

Conclusions: Yisaipu was effective and well-tolerated during the 24-week study period and was associated with a significant improvement in the signs and symptoms of active $\mathrm{nr}-\mathrm{axSpA}$

Disclosure of Interest: None declared

DOI: 10.1136/annrheumdis-2017-eular.3846

\section{THU0385 ASSESSMENT OF RELATIONSHIP BETWEEN BELIEFS' ABOUT MEDICINES AND TREATMENT ADHERENCE IN ANKYLOSING SPONDYLITIS PATIENTS}

M. Cinar ${ }^{1}$, F.I. Cinar ${ }^{2}$, E. Tekgoz ${ }^{1}$, R. Horne ${ }^{3}$, S. Yilmaz ${ }^{1} .{ }^{1}$ Department of Internal Medicine, Division of Rheumatology, University of Health Sciences, Gulhane Medical Faculty; ${ }^{2}$ Gulhane School of Nursing. University of Health Sciences, Ankara, Turkey; ${ }^{3}$ UCL School of Pharmacy, Centre for Behavioural Medicine, University College, London, United Kingdom

Background: Ankylosing spondylitis (AS) is a chronic disease requiring longterm treatment. Patients' beliefs about medicines and treatment may affect their treatment adherence and treatment success.

Objectives: In this study, we aimed to investigate the relationship between beliefs about medicines and treatment adherence in AS patients.

Methods: This cross-sectional study was conducted in a single tertiary rheumatology clinic. One hundred and fifty three AS patients were enrolled to the study. Socio-demographic and medical characteristics of the patients were recorded to a patient interview form. In order to evaluate the general and personal views of the patients about drugs, the Turkish Translation of the Beliefs about Medicines Questionnaire (BMQ-T) (Cinar et al in 2016) was used. According to this survey, the beliefs about medicines are composed of the following sections: Specific Necessity, Specific Concerns, General Overuse and General Harm. Medication adherence was assessed by using the Morisky Green Levine Medication Adherence Scale (MGLS) (1986). Adherence was measured on a scale of 0 to 4 , in which higher scores represent lower medication adherence and vice versa. Patients who reported a score of 0 on the MGLS were classified as adherent. All other patients were classified as nonadherent. Categorical variables were compared with Chi-square test, while continuous variables were compared with independent samples $t$ test. To evaluate potential risk factors for non adherence, logistic regression method was used.

Results: The mean age of the patients was $35.15 \pm 8.19$ years. The mean time from first symptom (disease duration) was $10.0 \pm 6.1$ years. The vast majority of the patients $(n=145 ; 94.8 \%)$ were male. One hundred patients $(65.4 \%)$ were using NSAIDs and 83 patients $(54.2 \%)$ were using anti-TNF. According to the MGLS scores, $56(36.6 \%)$ patients were compatible with treatment, and 97 patients $(63.4 \%)$ were found to be incompatible with the treatment. As the BMQ-T-Specific Necessity scores increased, drug compliance was also increased $(\mathrm{p}=0.006)$, on the other hand, as the BMQ-T-Specific Concerns, BMQ-T-General Overuse and BMQ-T-General Harm scores increased, drug compliance was decreased $(p=0.023,0.002,<0.001$, respectively). There were significant positive correlations between Specific Concerns $(p=0.002)$, General Overuse $(p=0.031)$ and General Harm $(p=0.024)$ score levels with the increase in patients' BASDAI score. While there was significant correlation between the disease duration and the General Overuse scores in the negative direction $(p=0.016)$, there was significant correlation between the disease duration and the Specific Necessity scores in the positive direction $(\mathrm{p}=0.002)$. As 1 unit increase in the BMQ-T-Specific Necessity score decreased the risk of treatment nonadherence by 0.38 fold, on the other hand, 1 unit increase in the BMQ-T-General Harm score raised the risk to 3.21 .

Conclusions: In our study, the belief of AS patients about the necessity of treatment they were using, found to increase treatment adherence, while harm potential of the treatment was decreasing the adherence. In other words, to enhance the treatment adherence of AS patients, it is essential to convince the patients about the necessity of treatment and relieve the anxiety they carry about potential adverse effects.

Disclosure of Interest: None declared

DOI: 10.1136/annrheumdis-2017-eular.4091

\section{THU0386 USE OF BIOLOGICS AND NSAIDS IN TREATING PATIENTS WITH AXIAL SPONDYLOARTHRITIS IN THE US-BASED CORRONA PSORIATIC ARTHRITIS/SPONDYLOARTHRITIS (PSA/SPA) REGISTRY}

P.J. Mease ${ }^{1}$, D. van der Heijde ${ }^{2}$, C. Karki ${ }^{3}$, M. Liu ${ }^{3}$, R. Pandurengan ${ }^{3}$, Y. Park ${ }^{4}$ J.D. Greenberg $3,5 .{ }^{1}$ Seattle Rheumatology Associates, Seattle, WA, United States; ${ }^{2}$ Leiden University Medical Center, Leiden, Netherlands; ${ }^{3}$ Corrona, LLC, Southborough, MA; ${ }^{4}$ Novartis, East Hanover, $\mathrm{NJ} ;{ }^{5}$ New York University School of Medicine, New York, NY, United States

Background: Axial spondyloarthritis (axSpA) is a chronic inflammatory disease affecting the sacroiliac joints and spine. Treatment primarily consists of first-line nonsteroidal anti-inflammatory drugs (NSAIDs) and/or biologic therapy when disease activity persists despite NSAID therapy. Although many studies have evaluated the efficacy of these treatments, there are few studies that have characterized NSAIDs and/or biologic therapy among patients with axSpA in the United States.

Objectives: To characterize patients with axSpA treated with NSAIDs only, biologics only, or both NSAIDs and biologics at the time of enrollment in the US-based Corrona PsA/SpA Registry.

Methods: This study included all patients with axSpA diagnosed by the rheumatologist aged $\geq 18$ years enrolled in the Corrona Registry between March 2013 and September 2016 who were treated with NSAIDs only, biologics only, or both NSAIDs and biologics at the time of enrollment (baseline). Patients fulfilled the Assessment of SpondyloArthritis international Society classification criteria. ${ }^{1}$ Demographics, clinical characteristics, disease activity measures and treatment history were collected at enrollment and described for each group.

Results: As of September 2016, 359 patients with axSpA met the study inclusion criteria; at baseline, 224 patients $(62.4 \%)$ were receiving NSAIDs (92 [25.6\%] with NSAIDs only and 132 [36.8\%] with both NSAIDs and biologics) and 135 patients $(37.6 \%)$ were receiving biologics only. Baseline characteristics were similar across all treatment subgroups with regards to age, race and body mass index. Fewer females were treated with biologics (with/without NSAIDs) compared to the NSAIDs only group. At baseline, patients treated with NSAIDs or both NSAIDs and biologics were older, had longer duration of disease with worse disease activity (measured by ASDAS and BASDAI), functional impairment (BASFI and HAQ-DI) and had worse pain and fatigue compared to those treated with biologics only (Table 1). $88-96 \%$ of patients receiving biologics (with or without NSAIDs) had prior biologic use compared to only $25 \%$ of NSAIDs only group. Patients treated with biologics only reported decreased percentage of impairment while working, overall work impairment and activity impairment at baseline compared with patients treated with NSAIDs only and both NSAIDs and biologics.

Table 1. Baseline clinical and patient-reported characteristics of patients with axSpA in the Corrona PsA/SPA Registry stratified by NSAID and biologic use

\begin{tabular}{|c|c|c|c|}
\hline Characteristics* & $\begin{array}{c}\text { NSAIDs } \\
\text { Only } \\
(n=92)\end{array}$ & $\begin{array}{c}\text { Biologics } \\
\text { Only } \\
(n=135)\end{array}$ & $\begin{array}{l}\text { NSAIDs and } \\
\text { Biologics } \\
(n=132)\end{array}$ \\
\hline Age, years & $48.6(15.0)$ & $46.1(13.6)$ & $48.1(13.2)$ \\
\hline White, n (\%) & $81(91.0)$ & $120(93.0)$ & $118(92.9)$ \\
\hline Male, $n(\%)$ & $53(58.9)$ & $88(65.7)$ & $91(70.5)$ \\
\hline $\mathrm{BMI}, \mathrm{kg} / \mathrm{m}^{2}$ & $29.4(6.1)$ & $29.7(7.1)$ & $28.7(6.1)$ \\
\hline Disease duration, years & $18.3(13.0)$ & $16.1(12.7)$ & $19.2(11.5)$ \\
\hline History of prior csDMARD use, $n(\%)$ & $23(25.0)$ & $55(40.7)$ & $47(35.6)$ \\
\hline History of prior biologic use, $n(\%)$ & $24(26.1)$ & $130(96.3)$ & $117(88.6)$ \\
\hline ASDAS-CRP & $\frac{24(20.1)}{2.1(0.7)}$ & $\frac{(100.0)}{1.9(0.8)}$ & $\frac{1(0.0)}{2.1(0.9)}$ \\
\hline BASDAI $(0-10)$ & $4.4(2.5)$ & $3.7(2.5)$ & $4.4(2.6)$ \\
\hline $\operatorname{BASFI}(0-10)$ & $3.7(2.9)$ & $3.1(2.8)$ & $3.5(2.9)$ \\
\hline Patient pain (VAS 0-100) & $49.9(29.5)$ & $37.3(28.7)$ & $44.4(30.5)$ \\
\hline Patient-reported fatigue (VAS $0-100$ ) & $\frac{45.0(29.0)}{47.1(29.4)}$ & $\frac{31.0(28.6)}{45.7(28)}$ & $49.9(30.7)$ \\
\hline Morning stiffness. n (\%) & $\frac{71.1(25.7)}{88(95)}$ & $\frac{43.1(8.0)}{114(84.4)}$ & $\frac{43.0(8.6)}{117(88.6)}$ \\
\hline HAQ-DI $(0-3)$ & $0.7(0.6)$ & $\frac{0.5(0.6)}{0.7)}$ & $0.6(0.7)$ \\
\hline \multicolumn{4}{|l|}{ WPAl-GH } \\
\hline Absenteeism (\% Work time missed) & $5.3(17.8)$ & $5.5(15.5)$ & $7.5(18.6)$ \\
\hline Presenteeism (\% Impairment while working) & $28.7(28.0)$ & $21.7(24.3)$ & $29.4(26.2)$ \\
\hline Work Productivity (\% Overall work impairment) & $26.1(26.4)$ & $22.8(25.7)$ & $32.5(37.7)$ \\
\hline Activity Impairment (\% Activity impairment) & $41.0(29.9)$ & $31.4(30.7)$ & $39.8(31.6)$ \\
\hline \multicolumn{4}{|c|}{$\begin{array}{l}\text { ASDAS-CRP, Ankylosing Spondylitis Disease Activity Score using C-reactive protein; BASDAI, Bath Ankylosing } \\
\text { SPondylitis Disease Activity Index; BASF, Bath Ankylosing Spondylitis Functional Index; BMI, body mass index; } \\
\text { HAQQ Health Assessment Questionnaire; VAS, visual analog scale; WPAI, Work Productivity and Activity } \\
\text { Impairment questionnaire: general health. } \\
\text { "All values are presented as "mean (SD)" unless otherwise stated. Current NSAID use included acetylsalicylic } \\
\text { acid, celecoxib, diclofenac, ibuprofen, meloxicam, naproxen and others. Current biologic use included abatacept, } \\
\text { adalimumab, anakinra, apremilast, certolizumab pegol, etanercept, golimumab, infliximab, rituximab, } \\
\text { secukinumab. tocilizumab and ustekinumab. }\end{array}$} \\
\hline
\end{tabular}

Conclusions: About two-thirds of patients with axSpA were treated with NSAIDs (with or without biologics) and about three-fourths of patients were treated with biologics (with or without NSAIDs) at enrollment. Patients that were already treated with biologics without NSAIDs at enrollment showed better measures of disease activity and PROs compared with the other treatment groups. Future research will assess changes in clinical and disease characteristics over time by treatment subgroup.

References:

[1] Rudwaleit M, et al. Ann Rheum Dis. 2009;68(6):777-783.

Acknowledgements: Corrona, LLC, has been supported through contracted subscriptions in the last 2 years by AbbVie, Amgen, BMS, Crescendo, Eli Lilly and Company, GSK, Horizon Pharma USA, Janssen, Momenta Pharmaceuticals, Novartis, Pfizer, Roche and UCB.

Disclosure of Interest: P. Mease Grant/research support from: Celgene, Novartis, AbbVie, Amgen, BMS, Lilly, Pfizer, UCB, Consultant for: Celgene, Corrona, 
Novartis, AbbVie, Amgen, BMS, Crescendo, Genentech, Janssen, Lilly, Merck, Pfizer, UCB, D. van der Heijde Consultant for: AbbVie, Amgen, Astellas, AstraZeneca, BMS, Boehringer Ingelheim, Celgene, Daiichi, Eli Lilly, Galapagos, Janssen, Merck, Novartis, Pfizer, Roche, Sanofi Aventis and UCB, Employee of: Imaging Rheumatology BV, C. Karki Employee of: Corrona, LLC, M. Liu Employee of: Corrona, LLC, R. Pandurengan Employee of: Corrona, LLC, Y. Park Employee of: Novartis, J. Greenberg Shareholder of: Corrona, LLC, Consultant for: Lilly, Genentech, Janssen, Novartis, Pfizer, Employee of: Corrona, LLC DOI: 10.1136/annrheumdis-2017-eular.1530

\section{THU0387 THE CLINICAL IMPORTANCE OF THE THYROID NODULES DURING TUMOR NECROSIS FACTOR-ALPHA INHIBITOR THERAPY IN PATIENTS WITH AXIAL SPONDYLOARTHRITIS}

R. Terlemez ${ }^{1}$, K. Akgün ${ }^{2}$, D. Palamar ${ }^{2}$, H. Sarı ${ }^{2} .{ }^{1}$ Physical medicine and rehabilitation, Şişli Hamidiye Etfal Research and Training Hospital; ${ }^{2}$ Physical medicine and rehabilitation, Istanbul University Cerrahpasa Faculty of Medicine, Istanbul, Turkey

Background: TNF is a pivotal regulator of inflammation and the cytokine system. Besides this, there is no doubt that TNF has a major role in cancer biology. TNF has a dual defensive and offensive role in carcinogenesis (1). TNF-blocking treatment has led to improvements in the management of inflammatory diseases. Even though their efficacy as anti-inflammatory drugs is well-proven, there are some concerns about the adverse effects of anti-TNF therapy (2). Basic research suggests that the evaluation of infections and malignancy as major adverse effects should be performed effectively (3). However, some studies conducted so far have dubious notions that anti-TNF therapy increases the risk of cancer $(3,4)$. Objectives: Objective: The clinical importance of the thyroid nodules in patients with axial spondyloarthritis (ax-SpA) rests with the need to exclude thyroid malignancy. The aim of this study is to assess the risk of thyroid malignancy in ax-SpA patients receiving anti-TNF therapy.

Methods: From September 2015 until December 2015, 70 patients diagnosed with ax-SpA according to ASAS criteria, were included in the research. Forty of the patients had received anti-TNF therapy, and 30 of the patients were anti-TNF naive. A clinician from the Physical Medicine and Rehabilitation clinic performed ultrasonography on all patients to screen for thyroid nodule(s). If thyroid ultrasonography revealed an abnormal finding, the patient was referred to a radiologist.

Results: The mean (SD) age was $38 \pm 9.87$ years; \% 75.7 of the patients were male. None of the demographic differences between the groups were statistically significant. Fifteen of the forty patients that received anti-TNF therapy and eleven of the thirty anti-TNF naive patients had thyroid nodule(s). Four patients from the anti-TNF group underwent fine needle aspiration biopsy, and two of them were diagnosed with papillary thyroid carcinoma. None of the nodules in anti-TNF naive patients required biopsy. When compared to the normal population, the standardized incidence ratio (SIR) was found to be increased in both male (SIR: $2.03 \% 95 \mathrm{Cl}: 1.9$ to 18 ) and female (SIR: $2.7 \% 95 \mathrm{Cl}: 2.6$ to 24 ) cases.

Conclusions: We see a mild increase in thyroid malignancies in ax-SpA patients that received anti-TNF therapy. Consequently, the thyroid gland should also be taken into consideration while screening for malignancy before anti-TNF therapy. References:

[1] Wajant, Harald. The role of TNF in cancer. Death Receptors and Cognate Ligands in Cancer. Springer Berlin Heidelberg, 2009. 1-15.

[2] Dixon, W. G., et al. Influence of anti-tumor necrosis factor therapy on cancer incidence in patients with rheumatoid arthritis who have had a prior malignancy: results from the British Society for Rheumatology Biologics Register. Arthritis care \& research 62.6 (2010): 755-63.

[3] Bongartz, Tim, et al. Anti-TNF antibody therapy in rheumatoid arthritis and the risk of serious infections and malignancies: systematic review and metaanalysis of rare harmful effects in randomized controlled trials. Jama 295.19 (2006): 2275-85.

[4] Askling, Johan, et al. Risks of solid cancers in patients with rheumatoid arthritis and after treatment with tumour necrosis factor antagonists. Annals of the rheumatic diseases 2005;64:1421-6.

Disclosure of Interest: None declared

DOI: 10.1136/annrheumdis-2017-eular.1013

\section{THU0388 EFFICACY AND SAFETY OF ADALIMUMAB IN PATIENTS WITH NON-RADIOGRAPHIC AXIAL SPONDYLOARTHRITIS: RESULTS FROM THE 28-WEEK OPEN-LABEL PERIOD OF THE ABILITY-3 STUDY}

R. Landewé ${ }^{1}$, J. Sieper ${ }^{2}$, R. Inman ${ }^{3}$, A.L. Pangan ${ }^{4}$, X. Wang ${ }^{4}$, J.K. Anderson ${ }^{4}$. ${ }^{1}$ University of Amsterdam, Amsterdam, Netherlands; ${ }^{2}$ Charité Universitätsmedizin Berlin, Berlin, Germany; ${ }^{3}$ Toronto Western Hospital, Toronto, Canada; ${ }^{4}$ AbbVie, North Chicago, United States

Background: Adalimumab (ADA) significantly improved clinical response at wk 12 vs placebo in patients (pts) with non-radiographic axial spondyloarthritis (nr-axSpA) in the ABILITY-1 study. The subsequent, ongoing ABILITY-3 study is assessing continuation vs withdrawal of ADA in nr-axSpA pts who respond to ADA.
Objectives: Evaluate the efficacy and safety of ADA during the open-label lead-in period of ABILITY-3.

Methods: ABILITY-3 has a 28-wk lead-in open-label ADA (40 mg every other wk) period; pts who achieve sustained remission (Ankylosing Spondylitis Disease Activity Score inactive disease [ASDAS ID] at wks 16, 20, 24 and 28) are randomized to double-blind placebo (withdrawal) or ADA (continuation) for 40 wks (ongoing). From wk 20-28, pts who did not achieve ASDAS ID were discontinued. Adult pts with nr-axSpA (fulfilling Assessment of SpondyloArthritis international Society [ASAS] criteria but not modified New York criteria) with objective evidence of inflammation in the sacroiliac joints or spine on MRI or elevated hs-CRP at screening; active disease at baseline (defined by ASDAS $\geq 2.1$, BASDAI $\geq 4$, and total back pain score $\geq 4$ ); and inadequate response to $\geq 2$ NSAIDs were eligible. Results: Of 673 pts enrolled, $51 \%$ were women and mean BASDAI was $7.0 \pm 1.4$ (Table). At wk 28, 305 (45\%) pts were randomized (ASDAS ID: $33 \%$ at wk 12, 44\% sustained at wk 28; nonresponder imputation) and $368(55 \%)$ pts discontinued (not achieving sustained remission, $n=300[45 \%]$; other reasons, $n=68[10 \%]$ ). In observed analysis, $59 \%, 35 \%$, and $22 \%$ of pts achieved ASAS40, ASDAS ID, and ASAS partial remission, respectively, at wk 12, similar to wk 12 data from ABILITY-1 pts with objective inflammation at baseline. The proportions of pts achieving ASAS20, ASAS40, ASDAS ID, ASDAS CII, and ASDAS MI increased, and mean BASDAl and back pain scores decreased over time (observed analysis; Figure). Adverse events (AEs) were reported by 468 pts (70\%), most commonly nasopharyngitis $(n=121[18 \%])$, upper respiratory tract infection $(n=81[12 \%])$, and headache $(n=56[8 \%])$; serious AEs occurred in $19(3 \%)$ pts.

Table 1. Baseline Characteristics

\begin{tabular}{lc}
\hline Mean \pm SD & $(\mathrm{n}=673)$ \\
\hline Age & $37.3 \pm 11.1$ \\
White, $n(\%)$ & $651(97)$ \\
Female, $\mathrm{n}(\%)$ & $343(51)$ \\
Symptom duration, $y$ & $7.7 \pm 7.7$ \\
HLA-B27 positive, $\mathrm{n}(\%)$ & $515(77)$ \\
TJC & $6.5 \pm 10.4$ \\
SJC & $1.9 \pm 4.0$ \\
MASES & $3.4 \pm 3.5$ \\
PGA-disease activity & $6.5+1.5 \mathrm{n}=671$ \\
Patient-pain & $7.4 \pm 1.7$ \\
BASDAI & $7.0 \pm 1.4$ \\
ASDAS & $3.6 \pm 0.8$ \\
hs-CRP & $9.6 \pm 15.0$ \\
BASFI & $5.3 \pm 2.2$ \\
HAQ-S & $2.1 \pm 0.6$ \\
\hline
\end{tabular}

BASFI, Bath Ankylosing Spondylitis Functional Index; HAQ-S, Health Assessment Questionnaire for the Spondyloarthropathies; hs-CRP, high-sensitivity C-reactive protein; MASES, Maastricht Ankylosing Spondylitis Enthesitis Score; PGA, physician global assessment; SJC, swollen joint count; TJC, tender joint count.
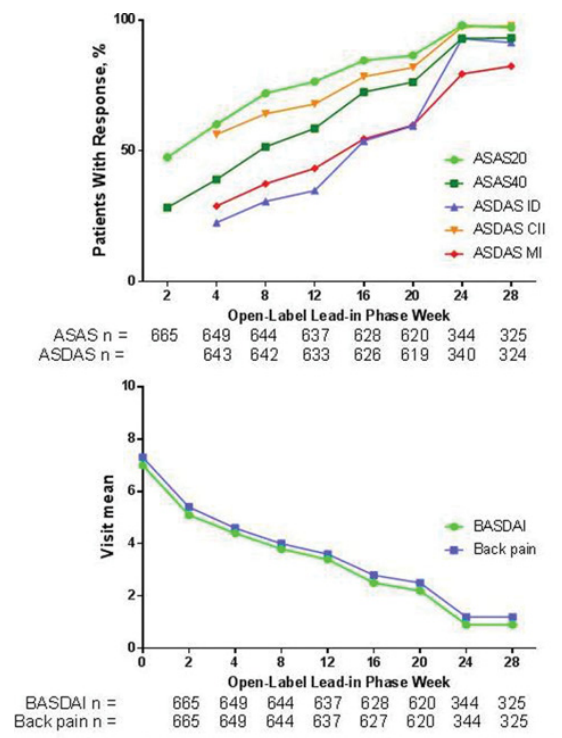

BASDAI, Bath Ankylosing Spondylitis Disease Activity Index; CII, clinically

important improvement, MI, major improvement.
Patients who did not achieve ASDAS ID were discontinued at week $20-28$ visits

Conclusions: Baseline disease activity was higher in ABILITY-3 pts than reported in prior trials. After 28 wks of open-label ADA therapy, disease activity improved and sustained remission was achieved in $44 \%$ of pts. Efficacy and safety in this nr-axSpA population were consistent with findings from ABILITY-1.

Acknowledgements: AbbVie funded the study and approved the abstract for submission. Medical writing support was provided by Maria Hovenden, PhD, of Complete Publication Solutions, LLC (North Wales, PA) and was funded by AbbVie.

Disclosure of Interest: R. Landewé Grant/research support from: Abbott, Amgen, Centocor, Novartis, Pfizer, Roche, Schering-Plough, UCB, and Wyeth, Consultant 